\author{
Journal of Analytic Divinity \\ International Refereed Journal \\ E-ISSN: 2602-3792 \\ Nisan/April 2021/ 5 (1): ss-pp 129-149
}

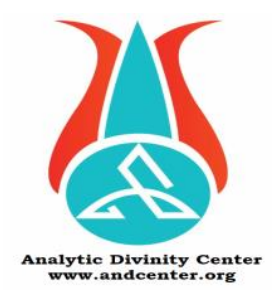

\title{
Tüketim Kültürünün Bir Örneği Olarak Kur'an'da Gösterişçi Dindarlık
}

Conspicuous Religiosity in the Qur'an as an Example of Consumer Culture

\section{Meryem Sümeyye Atmaca}

Ankara Yıldırım Beyazıt Üniversitesi İslami İlimler Fakültesi Ankara Yıldırım Beyazıt University Faculty of Islamic Sciences

Ankara, Türkiye, meryematmac@gmail.com

https:/ / orcid.org/ 0000-0002-4703-0691

Makale Bilgisi | Article Information

Makale Türü / Article Type: Derleme Makale/ Review Article

Geliş Tarihi / Date Received: 10 Şubat/ February 2021

Kabul Tarihi / Date Accepted: 12 Nisan / April 2021

Yayın Tarihi / Date Published: 15 Nisan /15 April 2021

Yayın Sezonu / Pub Date Season: İlkbahar-Nisan/ Spring-April

DOI: $10.46595 /$ jad. 881172

Cite as / Atıf: Atmaca Meryem Sümeyye. “Tüketim Kültürünün Bir Örneği Olarak Kur'an'da Gösterişçi Dindarlık", Journal of Analytic Divinity, 5/1 (April 2021): 129-149.

İntihal: Bu makale, iThenticate yazılımınca taranmıştır. İntihal tespit edilmemiştir. Plagiarism: This article has been scanned by iThenticate. No plagiarism detected. Web: http://dergipark.gov.tr/jad | e-mail to: editorjand@gmail.com

Copyright $($ Published by Özcan Güngör, Ankara Yıldırım Beyazıt Üniversitesi, İslami İlimler Fakültesi / Ankara Yıldırım Beyazıt University, Faculty of Islamic Studies, Ankara-Turkey. Bütün hakları saklıdır. / All right reserved. 
Öz

İnsanın yaşadığı her dönemde var olan ancak, dünya üzerinde son yüzyılda etkisi daha fazla hissedilir hâle gelen tüketim kültürü, sosyal yaşamdaki birçok dengeyi de etkilemiştir. Böylece tüketim, insanın ihtiyacına yönelik gerçekleştirdiği bir davranış olmaktan çıkmış ve artık insan, tüketmeyi bir ihtiyaç olarak görmeye başlamıştır. İnsan, varlığını tüketimle görünür hâle getirmeye çalışmıştır. Kapitalist düzenin hâkim olduğu dünyada, toplumdaki yabancılaşma artmıştır. Samimi insan ilişkileri yerini, daha bireysel ilişkilerin var olduğu küresel bir dünyaya bırakmıştır. İnsanlar, göstergelerle birbirlerine mesaj vermeye başlamışlardır. Bu göstergeler, genellikle marka değeri olan ürünlerdir. Bu çalışmada, tüketim kültürü bağlamında Kur'an'da gösterişçi dindarlığın görünümleri sosyolojik olarak ele alınmıştır. Araştırmanın amacı ise, tüketim kültürü bağlamında gösterişçi dindarlığın sosyolojik görünümlerini a) lüks tüketim ve yapılan harcamalar bakımından gösterişçi dindarlık, b) itikadi açıdan gösterişçi dindarlık ve c) ameli açıdan gösterişçi dindarlık yönünden ele almaktır. $\mathrm{Bu}$ çalışmada, açıklayıcı yöntem bağlamında tarihsel dokümantasyon tekniği kullanılmıştır. Öyle ki Kur'an, gösterişçiliği eleştirmiş ve dünya hayatının geçiciliğinden bahsetmiştir. Bu anlamda samimiyetle yapılmayan ibadetlerin kabul edilmeyeceğini ve katıldıkları ilim meclislerinin, münafıklara hiçbir faydasının olmayacağını vurgulanmıştır.

Anahtar Kelimeler: Tüketim Kültürü, Kapitalizm, Dindarlık, Gösterişçi Dindarlık, Kur'an'da Gösteriş

\section{Abstract}

The consumption culture, which existed in every period of human life, but whose effect on the world has become more noticeable in the last century, has also affected many balances in social life. Thus, consumption ceased to be a behavior carried out for the needs of human beings and people started to see consumption as a need. Man has tried to make his existence visible through consumption. In a world dominated by the capitalist order, alienation in society has increased. Sincere human relationships have given way to a global world where more individual relationships exist. People started to send messages to each other with signs. These indicators are generally products with brand value. In this study, the appearances of ostentatious religiosity in the Qur'an in the context of consumption culture are discussed sociologically. The aim of the study is to examine the sociological aspects of conspicuous religiosity in the context of consumption culture in terms of a) pretentious religiosity in terms of luxury consumption and expenditures, b) religious conspicuousness in terms of belief, and c) pretentiousness in terms of work. In this study, historical documentation technique was used in the context of explanatory method. So much so that the Qur'an criticized pretentiousness and talked about the transience of worldly life. In this sense, it was emphasized that prayers that are not performed sincerely will not be accepted and that the scientific assemblies they attend will not be of any use to the hypocrites.

Keywords: Consumer Culture, Capitalism, Religiosity, Pretentious Religiosity, Showiness in The Qur'an 


\section{Giriş}

Tüketim (consumption), üretilen veya yapılan ürünlerin kullanılıp harcanması, üretimin karşıtıdır. Tüketim, ihtiyaçları doyuracak "sarf etme"ler demektir (Ülken, 1969, 32). Yüzyıllar boyunca önemli kavramlardan birisi olmasına rağmen tüketim, son yüzyıldan itibaren farklı boyutlarıyla da incelenmeye başlanmıştır. Geçen yüzyıla kadar tüketim, daha çok iktisat biliminin ilgilendiği bir konu olmuştur. Günümüzde, başta sosyoloji olmak üzere psikoloji, siyaset bilimi, tarih, felsefe ve güzel sanatların ilgi duyduğu konular arasına girmiştir (Orçan, 2008, 22).

İnsanların harcamaları ve tüketim alışkanlıkları, ekonomiktir. Kişilerin harcamalarında psikososyal ve kültürel durumlar da ön plandadır. Alışılan yaşam standartları, yaşanan çevre ve kurulan insan ilişkileri, kişinin tüketim kültürünün oluşmasında oldukça önemli bir yere sahiptir (Tan, 2019, 195). Bir eşyanın tüketimi, yalnızca fiziksel değil, iktisadı, sosyoloji ve psikolojiyi de içine alan bir bütündür (Batı, 2015, 27). Tüketim toplumunda insan, bir nesneye ihtiyaç hisseder, daha sonra aldığ1 eşyanın gerçek ihtiyacı olmadığını, asıl ihtiyacının başka bir şey olduğunu düşünür. Öyle ki tüketim toplumunda ki bir insanın ihtiyaçları, hiçbir zaman son bulmaz (Aydoğan, 2015, 205). Tüketim sayesinde toplumda bireylerin kendilerine olan güveni artmaktadır. İnsanlar, tüketerek sahip oldukları iradeyi, yaşadıkları topluma kanıtladıklarını düşünmektedirler. Tüketimi, sosyal sınıfları belirlemede bir araç olarak kullanmaktadırlar. Neticede tüketim toplumunun, var olan bütün nesneleri yok etme anlayışı üzerine kurulduğu görülmektedir.

Tüketim kavramı üzerine çalışan ilk sosyal bilimci, Thorstein Veblen'dir. Veblen, gösterişçi tüketim kavramını kullanan ilk kişidir (Açıkalın vd., 2004, 6). Bu konunun işlenmesinde dönemin yaşam biçimi etkili olmuştur. Veblen, 1899 yılında yayımlanan kitabına Aylak Sınıfı ismini vermiştir (Orçan, 2008, 26).

Literatür incelendiğinde, tüketim kültürü ve gösteriş̧̧i dindarlık konusunda Kur'an merkezli bir çalışmaya rastlanmamıştır. Ancak doğrudan olmasa da dolaylı olarak "Gösterişçi Dindarlık" adlı çalışmasında Okumuş (2017) insanların gösterişe verdikleri önemi, birbirlerini gösteriş eşyalarıyla etiketlediklerini dile getirmiştir. Ayrıca o, insanların sosyal yaşamlarında da bu etiketler aracılığıyla etkileşim hâlinde olduklarını anlatmıştır.

Bu çalışmada tüketim kültürü bağlamında Kur'an'da eleştirilen gösteriş̧̧i dindarlık, sosyolojik olarak ele alınmıştır. Yine bu araştırmada gösterişçi dindarlığın sosyolojik görünümleri olarak düşünülen gösteriş ve lüks tüketim ve yapılan harcamalar bakımından gösterişçi dindarlık, itikadî açıdan gösterişçi dindarlık ve ameli açıdan gösterişçi dindarlık gibi konuların tüketim kültürü bağlamında incelenmesi hedeflenmiştir. Bu çalışmada açıklayıcı yöntem bağlamında tarihsel dokümantasyon tekniği kullanılmıştır. Kavramın sosyolojik boyutlarının anlaşılması için sosyoloji kitapları, sözlükleri ve konuyla ilgili makaleler incelenmiştir. Çalışmanın Kur'ani bağlamı ele alınırken de mealler ve çeşitli tefsir kitaplarından yararlanılmıştır.

Journal of Analytic Divinity, https://dergipark.org.tr/tr/pub/jad Volume 5/1 


\section{Tüketim}

İnsanların yaşamlarını devam ettirebilmeleri için fizyolojik, psikolojik ve sosyolojik ihtiyaçlar başta olmak üzere birçok ihtiyaçları bulunmaktadır. Bu ihtiyaçlarını karşılamak için yaptıkları harcamalar, tüketim olarak adlandırılmaktadır. İnsanların ihtiyaçlarının bir kısmı yaşamlarını devam ettirebilmeleri için önemli ihtiyaçlar olmaktadır. Fakat insanlar sosyal varlıklardır, dolayısıyla kimi zaman arzularını doyurabilmek adına tüketim yapmaktadırlar. İnsanların yaptıkları harcamaların nedeni ne olursa olsun, harcamalarının tamamı tüketim kavramının kapsamına girmektedir (Torlak, 2016, 21-22).

\section{1. Tüketim Kültürü}

Tüketimin oluşturduğu kültür, dünya üzerinde toplumun tüm tabakalarını kapsamaktadır (Duman, 2018, 203). Tüketim kültürü, pazar dinamiklerinin egemen olduğu toplumların kültürüdür. Bu nedenle tüketim kültürü, "yeni üretici güçlerin ortaya çıkmasıyla ve yüksek verimlilik gerektiren ekonomik bir dizgenin tekelci yeni yapılanmasıyla orantılı, yeni ve özgül bir toplumsallaştırma tarzıdır." (İlter, 2009, 3) olarak anlaşılmaktadır. Tüketim kültürü, sosyal, siyasal ve ekonomik özelliklerini kendisiyle bir uyum içinde bulundurur ve içinde hiçbir karışıklık yoktur (Orçan, 2008, 29). Toplumun alım gücünün yükselmesi ve bankalardan kredi alan insanların sayısının artması, tüketim toplumunun en önemli özelliğidir. Tüketim toplumunda insan, cebinde bulunmayan parayı da harcayan insan olmaktadır. (Demirezen, 2015, 11-45). Küresel boyutta tüketim kalıpları, insanların yaşam biçimlerini birbirine benzetmektedir. Bu bağlamda insanlarda yeni olana karşı büyük bir istek vardır. Bazıları ise tüketimi, çok yanlış olarak modernliğin ve gücün sembolü olarak algılanmakta olduğunu belirtmektedir (Eglitis, 2010, 434-445).

Tüketim kültüründe kapitalizm, en önemli kavramlardandır. Bu, 15. yüzyıl ortalarında Avrupa'da ortaya çıkmıştır. En genel anlamıla kapitalizm, "piyasa ekonomisinin zaferidir." (Özbolat, 2015, 85) olarak tanımlanmaktadır. Kapitalizmin hâkim olduğu toplumlarda ekonomi, kişisel çıkarlara ve bireysel özgürlüğe dayanır (Çiçek, 2012, 157). Bu sistemde malların kalite ve kullanım değerinden çok, işaret değeri önemlidir. Kapitalist sistemlerde insan, her türlü ihtiyacını karşılayabilmek için paraya sahip olmalıdır. Bu ideoloji, devamlı olarak insana ihtiyaçlar çıkaran, ardından onlara yönelik ürünleri piyasaya süren bir sistemdir (Ertit, 2014, 46). Modern toplumda kapitalizm, hem arzı hem de talebi üretir. Örnek olarak, yoğun çalışan bir iş insanının, tatil günlerinde dinlenebilmek için bir bahçe satın alması, bu sefer de aldığı bahçenin ödemelerini yapabilmek için daha yoğun mesai yapması gösterilebilir.

Gelir-gider dengesindeki eşitsizlik, topluma hâkimdir. Kapitalizmin sınırları birçok insan için görünür olmamakla birlikte, bu sistemin yasaları insanlar üzerinde oldukça etkili 
olmaktadır (Guevera, 2016, 86). Kapitalizmin, toplumlara benimsetmeye çalıştığ1 tüketim çerçeveleri, bireylerin yaşam alanlarını daraltmaktadır. Buna rağmen kapitalizm ürün çeşitliliğini artırmakta, insanlara sınırsız alternatifler sunmaktadır (Ertit, 2014, 46). Para kaygısı, kapitalizmde üreticilere hâkim olmakta, böylece maddi çıkar endişesi, samimi insan ilişkilerinin kurulmasını olanaksız kılmaktadır. Eşyalar, toplumsal kimliği ve sınıf ayrımını belirlemede önemlidir. Eşyalar; tutkularımızı, duygularımızı ve egomuzu tatmin ederler (Özcan, 2007, 144-145). Hazcı tüketim insana yapay mutluluklar sağlamakta ve onu, sürekli yeni ihtiyaçları olduğuna inandırmaktadır. Tam olarak kapitalizm de bunu amaçlamaktadır. Bu bağlamda "duyguların deneyimi yarattığı ve duygusal kodun da tüketiciyi oluşturduğu" (Bat1, 2015, 161) ifade edilmektedir.

Kapitalizmin hâkim olduğu toplumlarda, elde ettikleriyle yetinmeyen, onları çabucak tüketen ve ihtiyacından daha fazlasını kazanma hırsı olan insanlar vardır. Dolayısıyla tüketim kültürü, bu tür toplumlarda oldukça yüksektir (Köroğlu, 2012, 30). Kapitalizmin hâkim olduğu toplumlarda rekabet, ekonomiyi düzenleyen en temel faktör olarak görülmektedir. Bu bağlamda rekabet, toplumların gelişmesini, zenginleşmesini ve ekonominin canlanmasını sağlar (Demir, 2012, 4-6). Kapitalizmde durgunluğa yer yoktur, dişleri durmadan dönen bir çark gibidir. Kapitalizm sayesinde zengin daha da zenginleşmiş, fakir ise daha da fakirleşmiştir. Toplumlarda ekonomik dengenin bozulması, sosyal alan da dâhil olmak üzere birçok dengeyi alt-üst etmiştir. İnsanlar arasındaki ekonomik farklılıkların artmasıyla birlikte, toplumda insanlar arasında sınıflar oluşmaya başlamıştır. Bu sınıflar, batı toplumlarında burjuvazi ve proletarya olarak adlandırılmıştır. Ekonomik olarak toplumun en varlıklı sınıfını oluşturan burjuvaziler, aynı zamanda iş gücünü ucuzlatan yöneticiler konumundadırlar. Buna karşın proletarya ise emeği sömürülen alt tabakadır. Bu durumda tüketim toplumlarında bireylere söz hakkı veren, toplum yönetimini şekillendiren güç, tüketim olmaktadır (Demirezen, 2015, 34).

Tüketim, sosyal sınıfların kendilerini ifade etme biçimi olarak da kendini gösterebilmektedir. Sosyal statülerin gösterişle belirlendiği toplumlarda insanlar, ihtiyaçlarını geri plana atmakta, buna karşın gösteri imgelerini öne çıkarmaktadırlar (Saad, 2007 , 92). Statülerin belirlenmesinde tüketimin ön planda olduğu toplumlarda insanlar, birbirlerine sahip oldukları değerler üzerinden değer atfetmemekte, aksine sahip olunan metalar üzerinden değer yüklemektedirler (Batı, 2015, 35). Bu durum, Veblen'in Aylak Sınıfın Kuramı isimli kitabında bahsettiği gibi gösteriş̧̧i insanların oluşmasına zemin hazirlamaktadir (Veblen, 2020, 51). ${ }^{1}$

Maslow, insanın ihtiyaçlarını hiyerarşik biçimde incelemektedir. Ona göre çevre, insanların ihtiyaçlarını belirlemede çok etkili olmaktadır. İhtiyaçlar, genellikle biyolojik veya içgüdüsel olarak tasvir edilmektedir. Temel bir ihtiyacın karşılanması, bir üst

\footnotetext{
${ }^{1}$ Gösterişçi insanlar, gereksiz eşyalara yüksek para ödeyerek sahip olurlar. Öyle ki bunların giyimleri, evdeki eşyaları, hatta evdeki yardımcıları bile gösteriş içindir. Davranışlarındaki tek ve asıl amaç, kendilerini çok zengin gibi göstermek ve insanlardan parayla sayg1 satın almaktır. (Veblen, 2020, 15-30)
}

Journal of Analytic Divinity, https://dergipark.org.tr/tr/pub/jad Volume 5/1 
basamaktaki ihtiyacı ortaya çıkaracaktır. Hiyerarşi piramidinin ilk üç basamağında bulunan fizyolojik, güvenlik ve sosyal ihtiyaçlar düzenli olarak giderilmekte buna karşın üst kısımda yer alan saygınlık ve kendini gerçekleştirme ihtiyacı daha az insan tarafından karşılanabilmektedir (Parıltı, 1999, 270; Maslow, 2011, 163). Toplumda konumu yükselen kişi, aynı zamanda piramidin tepesine yükselmektedir. Az gelişmiş toplumlarda tüketim, hiyerarşideki fizyolojik ve güvenlik ihtiyaçlarını karşılamayı amaçlamaktadır (İslamoğlu vd., 2010, 72). Yeni ihtiyaçlar üreten kapitalizmin etkisiyle, günümüzde insanların tüketim kültüründe bazı değişimler görülmektedir. Bu durumda sıralama, Maslow'un ihtiyaçlar hiyerarşisindeki gibi gerçekleşmemekte, buna karşın insanların ihtiyaç olarak gördüğü nesneler farklılaşmaktadır. Neticede tüketimde belirleyici etken, bireyin temel ihtiyaçları olmaktan çıkmaktadır. İnsanların istekleri, ihtiyaçların belirlenmesinde belirleyici konuma gelmektedir. İstek ve arzulara yönelik gerçekleştirildiği için böylesi bir tüketimin sonu, asla gelmeyecektir. Eğlencenin ön planda olduğu tüketimde insan, mutluluğa ulaşmayı amaçlamaktadır. Tükettiklerini ödeyebilmek için durmaksızın çalışan insan, amaçladığı huzura da hiçbir şekilde ulaşamamaktadır (Dal, 2017, 12).

Üretim yapan sanayi sektörü işletmeleri, fabrikanın ihtiyaçlarını karşılayabilmek ve hedefledikleri kâr payına ulaşabilmek için, üretim miktarlarını belirli bir bantta tutmaları gerekmektedir. Dolayısıyla insanlar, daha fazla tüketime teşvik edilmektedirler. Tüketim toplumlarında parola, içinde bulunulan ânı yaşamaktır. Bu toplumlarda "hayat kısa, hayatını yaşa" gibi sloganlar da yaygındır. Kişi, arzu ettiği ürünü hemen almalıdır. Yaşadığ günü, hayatının son günü gibi düşünmeli, isteklerini gerçekleştirmelidir. Çünkü sistem, tüketimi belirsizliğe bırakmayı istememektedir. Tüketim çarkı, pazara sunulan malı, bir an önce satmayı ve yeniden üretmeyi hedeflemektedir. Kişi cebindeki parayı, vakit kaybetmeden istekleri için kullanmalı, tasarruf yapmamalıdır. Hatta kişinin cebinde para olmasa dahi buna bir çözüm yolu bulunmalıdır. Bu durumda kapitalizmin vazgeçilmez sistemi bankalar ve onların kredileri devreye girmektedir. Kredi kartları, insanlara para vermeden alma hissiyatını yaşatmaktadır. Şimdi harca, sonra öde anlayışı hâkim olmaktadır (Duman, 2018, 208). İnsanlara isteklerini hemen gerçekleştirmesi gerektiği her daim vurgulanır. Erteleyen insan kendini yetersiz hisseder. Tüketim toplumu "şimdi" toplumudur (İnce vd., 2018, 74-75).

Üretimde üretici söz sahibidir. Tüketici, üretilen eşyalara göre isteklerini şekillendirir. Üretici ürünü üretir, onu pazara sunar. Yenilik arayan insanlar da bu ürüne ihtiyacı olduğunu düşünerek satın alma eylemini gerçekleştirir (Demirezen, 2015, 45). Suni ihtiyaçlar, tüketim isteğini harekete geçirir. Böylece toplumlar, "tüketim toplumu" hâline gelmektedirler (Demir, 2012, 6-7).

Tüketim toplumlarında insanlara tüketim alışkanlığını benimsetebilmek için hatırı sayılır ekonomik yatırımlar yapılmaktadır. Pazarlama politikaları, sosyal medya kaynakları 
ve reklam yöntemleri, oldukça önemlidir. Öyle ki reklam tasarımlarına, kullanılan renklere, fonda çalan seslere kadar her şeye düşünülmekte, tüketicinin alma isteğini harekete geçirmek ve ürünü satmak amaçlanmaktadır. İnsanların alışverişlerdeki tutum ve davranışlarını, medya ve reklam sektörü belirlemektedir (Çınar vd., 2010, 277-278; Demirel vd., 2015, 125-129; Solomon vd., 2010, 17).

\subsection{Tüketim Kültürünün Bireysel ve Toplumsal Perspektiflerden İncelenmesi}

Tüketimin sembolik yönden bireysel ve toplumsal etkisi, önemli bir husustur. Kişilerin tüketim alışkanlıklarının şekillenmesinde yaşadıkları toplum, benimsedikleri dinî inançlar, oldukça büyük bir önem arz etmektedir. Dahası bireyin yetiştiği toplumun kültürü, alışkanlıkları ve bireyin eğitim seviyesi de oldukça önemli görülmektedir. İnsanlar, satın aldıkları ürünlerin markası, kalitesi ve modaya uygunluğuyla birbirleriyle sözsüz iletişim kurmakta ve birbirlerine mesaj vermektedirler. Bireyler, benimsedikleri tüketim alışkanlıklarıyla sosyal düzeni ve anlamları inşa etmektedirler (İlter, 2009, 9). Eşyanın işaret ettiği değer üzerinden statü sağlayacağını düşünen insan, bunun sonucu olarak kendine, değerlerine ve kültürüne yabancılaşmaktadır. Tüketim, kapitalizmin de etkisiyle yabancılaşmayı ve kimlik krizlerini de beraberinde getirmektedir (Demirezen, 2015 , 38). Toplumda bireyler arasında yabancılaşma, uzaklaşma ve nesneleşme hüküm sürmektedir (Batı, 2015, 55).

Tüketimin bir diğer şekli ise gösterişin ön planda olmasıdır. Toplumda statüsünü yüksek göstermek isteyen insan, gösterişe yönelmektedir. Yani statüyü yüksek göstermeye bağlı bu tüketim, lüks harcamalar kısmına girmektedir. Bu kişiler, kullandıkları ürünlerin ne kadar lüks ve pahalı olursa, yaşadıkları toplumda o kadar saygın olacaklarını ve otorite sağlayacaklarını düşünmektedirler. Lüks ürün tüketimi, bireylerin saygın bir referans grubuyla uyum sağlama arayışından ibarettir. (İlter, 2009, 471).

Bocock, tüketim konusunda: "Tüketim, artık insanların kim oldukları, kim olmak istedikleriyle ilgili duyarlılıklarını ve bu duyarlılıkları korumalarını sağlayan yöntemleri etkilemektedir. Kimlik duygusunun gelişimini çevreleyen olgularla iç içe geçmiş durumdadır. Bu nedenle tüketim, ekonomik olduğu kadar, toplumsal ve kültürel bir olgudur." (Bocock, 2009, 10) ifadelerini kullanmıştır. Tüketim ve istekler birbirinden ayrı düşünülemez. İstekler, tüketimi canlı tutar (Öztaş vd., 2020, 116). Tüketim, yirminci yüzyıl sonlarına doğru tanrısı olmayan ve pratikleri tüketmekle yerine getirilen din hâline gelmiştir (Yanıklar, 2006, 11).

\subsection{Dindarlarda Tüketim Kültürü}

Din, insanın yaşamında manevi ve psikolojik ihtiyaçlarını karşılamaktadır. Dinin etkisiyle, toplumun sosyolojik kodları oluşmaktadır. Tüketim ise maddi ihtiyaçları karşılar.

Journal of Analytic Divinity, https://dergipark.org.tr/tr/pub/jad Volume 5/1 
Dindarlık, kişinin mensubu olduğu dinin kurallarına uyma, dininin pratikleri yerine getirmesi ve bunları içselleştirerek yaşamının her alanında uygulamasıdır (Kurt, 2009, 3). Dindarlık, kişinin günlük yaşamında inancına bağlanma derecesini gösteren bir olgudur. Kişinin yaşı, sosyoekonomik durumu, yetiştiği ortam ve eğitim seviyesine bağlı olarak değişmektedir. Denilebilir ki dindarlık, kişinin din algısına bağlı olarak bir görecelilik göstermektedir (İnce vd., 2018, 68). Dindarlık, kişiye özgüdür. Dünya üzerinde yaşayan kişi sayısı kadar dindarlık anlayışı bulunmaktadır. Dindarlık tiplemeleri bakımından incelendiğinde dindarlığın, inançsızlık, gösterişçilik, taklidi, tahkiki ve zevk alınan dindarlık gibi boyutları da ele alınmıştır (Okumuş, 2017, 42). Bu çalışmada ele alınan dindarlık tipolojisi ise "gösterişçi dindarlıktır."

Dindarlık ve satın alma süreci arasında doğrudan bir ilişki vardır. Bireyin dindarlık düzeyine göre marka tercihi ve satın alma kıstası değişmektedir. Bu durum tüketilenlerin hepsini kapsamayabilir. İnanılan dinin kesinlikle yasakladığı ürünler vardır ki bu kurallar oldukça etkilidir. Bir Müslüman, alkol içeren bir ürünü dinî hassasiyetlerini göz önünde bulundurarak satın almaz. Hindistan'da inek ve sığıra saygı duyulduğu için bunların etlerini tüketmek yasaktır. Ama söz konusu bir ceket yahut bir elbise için dikkat edilen dini hassasiyetler daha esnektir. Tüketim alışkanlıkları bağlamında dindarlık, inanılan dinin emir ve yasakları, bireylerin din algıları ve dindarlık seviyelerine göre farklılık gösterir (Haşıloğlu vd., 2012, 16).

1980'den sonra ekonomide finansal serbestleşmelerle alım gücü artan Müslümanların, kapitalizmin etkilerini hissettikleri bilinmektedir. Batıyı göz önüne alarak yaşamlarını yeniden biçimlendirdikleri, ama dinlerini de yaşamaya devam ettikleri görülmektedir. Müslümanların değişen tüketim odaklı yaşam biçimleri, toplumsal normların değişmesine de yol açmaktadır (Özbolat, 2015, 19). İslam'ın emrine göre tesettürün amacı dikkat çekmemek iken, yeni dönem muhafazakârları, "moda" adı altında kıyafetleriyle kendilerini daha belirgin hâle getirmekte ve bazılarının tesettürü bir aksesuar olarak kullandıkları görülmektedir. Bunlar, yeni oluşan tüketim kodları sayesinde, sosyal yaşamda kendilerine yeni bir konum elde etmektedirler (Demirezen, 2015, 11-70). Oysaki İslam ve moda kelimelerinin yan yana getirilmesi bile mümkün olmamaktadır.

Bu durumda olanlar, tesettüre çift yönlü bir görev atfetmektedirler. Böylece tesettür, hem kadının sosyal yaşamda fark edilmesini sağlamakta hem de kendilerine bir sınır koymaktadırlar. Neticede dindar kadın, "hem Müslüman hem de modern olabilmektedir (Göle, 2012, 41). Göle, dindarlardaki bu değişimi, "İslam'ın Yeni Kamusal Yüzleri" olarak isimlendirmektedir. Moda ve takva kelimeleri karşı karşıya gelmektedir (Pişkin, 2016, 10). Maddi refahın yükselmesiyle tasavvufi etkinlikler ile hac-umre ziyaretlerinin arttığ bilinmektedir. Ancak bu ibadetler, bir yerden sonra ibadet olmaktan çıkarılmakta ve din gezilerine yani " inanç turizmine (Demirezen, 2015, 14)" dönüştürülmektedir. Fakat yapılan 
çalışmalar, cami cemaatlerinde herhangi bir artış olmadığını göstermekte, aksine cemaat oranlarının giderek azaldığı anlaşılmaktadır. Sonuçta muhafazakârların günlük yaşamlarına ve dini pratiklerine ilişkin bahsettiğimiz bu hususlar, kapitalizmin kültürel formlarıyla uyum sağlayan örnekler olarak karşımıza çıkmaktadır (Özbolat, 2015, 83). Bu veriler, muhafazakârlarda seküler hayatlarıyla ilgili bilgi vermektedir.

$\mathrm{Bu}$ yeni trendde İslam ile kapitalizm ve dindar ile seküler kavramları, bir araya getirilmektedir. Oysaki kapitalizm ve İslam'ın aynı sınırlar içinde olduğunun söylemesi mümkün değildir. Kapitalizmde insana aşılanan tüketim kavramını, İslam dini israf olarak görmektedir. İslam'da ölçülü olmak esastır. Kapitalizmin tanrısı üretim, mabedi ise tüketimdir. Hatta AVM'ler, kapitalizmin tüketim mabetleri olarak telakki edilmektedir. İslam ise bunlara karşı net bir karşı duruşu simgelemektedir. Dindar bireyler, dindarlık ile kamusallığı, Müslümanlık ile çağdaşlığı birleştirmenin yollarını aramakta, ancak ikisinin de anlamını yitirmektedirler (Göle, 2012, 46). Belki burada çă̆daşlık yerine gelmektedir, ancak Müslümanlık namına çok değerler yitirilmektedir. İslam dini, son dönemlerde ortaya çıkan hem seküler hem dindar tipolojisinden de oldukça zarar görmektedir. Yine kamusal alanda dindarlık belki kendine yer bulmakta ise de dindarlık, hep zemin kaybetmektedir.

Tüketim kültürü ile toplumun kültürel yapısındaki değişimlerin, kapitalizmin ve dindarlığın anlamı ve bağlamı üzerinde oluşturduğu etki, sınırların belirsizleşmesidir. Pratikte seküler ve dindar kesimler, ayrı değillerdir, ama muhalif olarak açıkça karşı karşıya da gelmezler. Aralarındaki sınırlar belirsizdir ve sürekli değişim içindedir (Özbolat, 2015, 84). Tüketim kültürünün dindarlığa etkisini inceleyen Miller'a göre (2003), tüketim kültürünün dinî inançların değerini düşürmemektedir fakat dinin gerektirdiği pratikleri etkilemektedir (Özbolat, 2015, 155'den atfen Miller, 2003). Dini hassasiyetleri yüksek bireyler, tüketim kültürünün dini "metalaştırdığını" düşünmektedirler (Özbolat, 2015, 173). Weber, John Wesley'in bu konu hakkındaki sözlerini dikkat çekici biçimde aktarmaktadır: "Korkarım ki, zenginliğin arttığ1 yerde dinin içeriği aynı ölçüde azalmıştır. Bu yüzden de eşyanın doğasına uygun olarak, gerçek bir dinin yeniden doğuşunun uzun süre kalıcı olabileceğini olanaklı görmüyorum. Çünkü din, hem çalışkanlık hem de tutumluluk üretmek zorundadır ve bunlar da ancak zenginliğe yol açar. Fakat zenginlik artınca, gurur, kızgınlık ve dünya sevgisi de artacaktır." (Weber, 2008, 151).

\section{Gösteriş̧̧i Dindarlık}

Gösteriş kelimesinin Arap dilindeki karşılığı, riyadır. Bu sözcük Farsça'da nüma yani gözükmek fiili ile karşlanmaktadır. Bu durumda gösteriş hem göstererek hem de duyurarak yani süm'a olmaktadır. İnsanın kendini bir nevi vitrinleme çalışmasıdır. Gösterişçi dindar, olduğu gibi görünmez, göründüğü gibi de değildir (Okumuş, 2017, 30). Hareketlerinin temel motivasyonu, dünya hayatından zevk almaktır. Kişisel çıkarları ön planda olur, dini pratik ve kuralları kendi çıkarları için kullanmaktadır. Dinî inanç ve

Journal of Analytic Divinity, https://dergipark.org.tr/tr/pub/jad Volume 5/1 
pratiklerin kendilerine gerçekten fayda sağladığına inanmamakla birlikte girdikleri ortama göre de farklı rolleri benimsemektedirler (Hökelekli, 2001, 76). Dinini kişisel menfaatlari uğruna kullanan insanlar hakkında Allport'un dış güdümlü dindarlık ifadesinin kullanılması doğru olacaktır (Allport, 2004, 13). ${ }^{2}$

Gösteriş yapan insanın hareketleri abartılıdır, ilgiden beslenir ve ikiyüzlüdür. Sayg1, statü elde etme, toplumda kabul görmeme korkusu vs. gibi nedenlerden dolayı kişinin iç benliğini yansıtamaz. Başrol, her zaman sosyal benliğindir. İhtiyaçtan doğan isteklerimiz olduğu gibi, gösterişten doğan isteklerimiz de vardır. Eşarp takmak, dinî bir sorumluluk iken, marka eşarp takarak bunu insanlara göstermek, gösterişten kaynaklanmaktadır (Köroğlu, 2012, 80). Gösteriş yapan insan, birden fazla kişiliğe sahiptir. Benimsediği veya inandığ1 değerleri ve düşünceleri yoktur. Gösterişçi insan, kendisini diğer insanlardan değerli görmektedir. Kendini beğenmektedir ve oldukça bencildir. Yine bu insan, övülmeyi sever. Giyim kuşamını ve davranışlarını toplumdan övgü kazanma arzusuyla şekillendirir. Gösterişçi dindar, herhangi bir konuda kendisinden daha iyi bir insan olmasına tahammül edemez ve haset eder. Her durumda haklı çıkma arzusu bulunmaktadır. Davranışlarında tutarsızlıklar bulunmaktadır. Katıldığı toplumun düşüncelerini ve inançlarını benimsemiş gibi görünmekle birlikte bu davranışlarından ötürü bu kişilerde karakter bozukluğu, kaygı, şüphe, güvensizlik, korku gibi psikolojik rahatsızlıklar da bulunmaktadır (Okumuş, 2017, 115-148).

Gösterişçi dindarlığın din istismarı olduğunun söylenmesi yerinde olacaktır. Çünkü kişisel menfaatler uğruna, toplumun kutsalları, değerleri ve hassasiyetleri ya itibarsızlaştırılmakta ve basitleştirilmektedir. Bu manada bir ayette "Zalim olanlar ise yalnız kendilerine verilen refahın ardına düştüler."(Hud, 11/116) denilmektedir. (Diyanet Meali, Altuntaş). Oysa din, dünya hayatında insanın kalbinin gösterişe kaymaması gerektiği vurgulamaktadir.

Gösterişin gerçekleştirileceği zaman ise en çok fayda sağlanacă̆ı, gösterişçi dindarın amacını gerçekleştirebileceği en uygun zamandır. Kıyafet, yapılan ibadet, söylenen sözler, gerçekleştirilen davranışlar, gösterişçi dindarlığın ayrılmaz vasıtalarındandır (Okumuş, 2017,49). Gösterişçi dindarların elde etmek istedikleri çıkarlar, kişiden kişiye göre farklılık göstermektedir. Kimilerinin amacı maddi yönden fayda sağlamak iken kimilerinin amacı da itibar ve saygınlık kazanmak olmakla birlikte bu davranışların altında yatan sebepler kişiden kişiye göre değişiklik göstermektedir. Bazı insanlar, toplumda saygınlık kazanmayı amaçlarken, bazıları da dini otorite sağlamayı hedefleyebilir.

\footnotetext{
2 Dış güdümlü dindarlıkta dinî değerler, öncelikli olarak bir anlam taşımamaktadır. Bu bağlamda kişisel çıkar ve istekler ön planda olmaktadır. Bunun yerine fonksiyonel din kavramı da kullanılabilmektedir.
} 


\subsection{Gösterişçi Dindarlı̆̆ın Boyutları}

Gösterişçi dindarlığın en önemli nedenlerden biri, toplumun sosyal yapısıdır. Toplumda kabul gören ve uygulanan dine tabi olmadıkları hâlde bireyler, topluma uyum sağlayabilmek adına o dini kabul ediyor gibi görünebilir. Dinin büyük ölçüde referans olma ve meşrulaştırma gücü bulunmaktadır (Subaşı, 2004, 148). Dini çıkarları uğruna kullanan kimseler, toplumda güvene dayalı sosyal ilişkiler kuramazlar. Bu durum Kur'an'da "Onlar, iman edenlerle karşılaştıkları zaman 'İman ettik.' derler..." (el-Bakara, 2/14) ayetiyle dile getirilmektedir. Bunun toplumda sosyal ve siyasal yaşamda kabul görmek gibi nedenleri vardır. Takiyyenin bireye ve dine olumsuz etkileri bulunmaktadır. Psikososyal araştırmalara göre çevrenin baskısını hisseden insanlar, içinde bulundukları çelişkiden kurtulmak için kendilerini aldatma yoluna gitmektedirler. Onlar, toplumun normlarına görünüşte uymaktadırlar fakat kendilerini istemedikleri bir şeye zorladıkları için psikolojileri de olumsuz etkilenmektedir (Koç, 2017, 97). Bu durum Kur'an'da, “Sizler niçin yapmadıklarınızı söylüyorsunuz?" (el-Saff, 37/2) ayetiyle sorgulanmaktadır. Bu aşamada diğer inanç ve kabullere de saygı duyulduğu takdirde, toplumda samimiyet artacak, gösteriş azalacaktır.

Damgalama, gösterişçi dindarlığın sosyolojik nedenlerinden biri olarak değerlendirilmektedir. Toplumların geçmişten bu yana getirdikleri normları vardır. $\mathrm{Bu}$ normların dışına çıkanlar, kimi toplumda bazen yaftalanmaktadır. Bu durumda insanlar, ayrımcılığa uğramaktan ve statü kaybetmekten sürekli olarak çekinmektedirler. Damgalanmış olan insan, toplum önünde daha az değerli olan insandır. Böylece toplum tarafından etiketlenen kişi, toplumda azınlık olarak kalmaktadır (Adler-Nissen, 2014, 147). Damgalamadan kurtulmak isteyen birey ise farklı bir özelliğiyle öne çıkmakta ve böylece, olumsuz yanını perdelemeye çalışmaktadır. İnsanlar arasında sözüne güvenilmeyen bir kişi, damgalanmaktan korktuğu için ihtiyaç sahiplerine maddi açıdan cömert yardımlarda bulunabilir. Ya da cezaevinden yeni çıkmış bir insan, toplum nezdinde itibarını yeniden kazanabilmek için namazlarını düzenli olarak camide kılabilir. Damgalanmaya karşı geliştirilen davranışları insanların başa çıkma yolu olarak değerlendirmek mümkündür.

Bir diğer toplumsal neden de sosyal kontrolün oldukça baskın olmasıdır. Sosyal kontrol, toplumsal normların benimsenmeye zorlanmasıdır. Farklı düşünen bireyin kendini toplumda güvensiz hissetmesi veya topluma uyum sağlayabilmek adına gerçekleştirdiği davranıştır. Sosyal kontrol, bireylere sınırlar belirlemektedir. Söz gelimi bir kimsenin babasının imam olduğu biliniyorsa ve birey ramazan ayında oruç tutmuyorsa, bu durum toplum tarafından hoş karşılanmamaktadır. Dolayısıyla babası imam olan birey, oruç tutmadığını kimseye söylememektedir, tutuyormuş gibi davranmaktadır. Allah'a karşı sorumluluğunu yerine getirmeyen insan, Allah'tan değil de toplumun çekinir hâle gelmektedir. Özet olarak söylemek gerekirse, gösterişçi dindarlığın toplumsal boyutlarına, statülere ve fikirlere meşruiyet kazandırma yollarından en önemlisi, dindir (Okumuş, 2017, 154-194).

Journal of Analytic Divinity, https://dergipark.org.tr/tr/pub/jad Volume 5/1 


\section{Kur'an'da Tüketim Kültürü Bağlamında Gösterişçi Dindarlık Tipolojileri}

Gösterişçi dindarlık tiplerini, lüks tüketim ve yapılan harcamalar bağlamında gösterişçi dindarlık, ameli gösterişçi dindarlık ve itikadi gösterişçi dindarlık olmak üzere üç kısma ayırabiliriz. Lüks tüketim ve yapılan harcamalar bağlamında gösterişçi dindarlıkta kişi, küresel tüketim kodlarını kullanarak toplum nezdinde statü kazandığını düşünmektedir. Ameli gösterişçi dindarlıkta kişi, samimiyetle, Allah rızası için yapılması gereken bir ibadeti, insanların rızasını kazanmak ve kişisel çıkarlar uğruna yapmaktadır. Yine o, eylemlerinin karşılığını Allah'tan değil de insanlardan beklemektedir (Özdemir, 2015, 156). İtikadi gösterişçilik ise münafıklık olarak kabul edilmektedir. Yani inanmadığ halde, toplum içinde inanyormuş gibi görünmektir. (Okumuş, 2017, 30). Oysaki bir dine inandığını ifade eden bireyler, inandıkları dinlerdeki dini pratikleri herhangi bir çıkar kaygısı düşünmeden yerine getirmelilerdir.

\subsection{Lüks Tüketim ve Yapılan Harcamalar Bağlamında Gösterişçi Dindarlık}

Gösterişçi dindarlığın bir diğer boyutunda da lüks tüketim yer almaktadır. Kendilerinin toplumdaki bireylerden daha seçkin olduğunu düşünürler. Gösteriş yapan insanlar, tüketimin sınırlarını büyük ölçüde aşmaktadır. Maddi, manevi, sosyal ve siyasal çıarları uğruna, israfa yönelmektedirler (Okumuş, 2017, 256). Sahip oldukları her şey, onlar için birer gösteriş aracı olmaktadır. Öyle ki gösterişçi insanlar, sahip olmadıklarıyla da övünürler. Bireyler, marka değeri olan kıyafetlerle toplumda kabul görürler. Kişilerin fikirleri değil, kıyafetleri ön plandadır. Bu durumda sözlerinin değeri olmayan kişiler, fikirlerini topluma empoze etmeye çalışacaklardır. Bir ayette bu duruma "Onları gördüğ̈̈̈n zaman kalıplan hoşuna gider. Konuşurlarsa sözlerine kulak verirsin. Onlar sanki elbise giydirilmiş kereste gibidirler. Her kuvvetli sesi kendi aleyhlerine sanırlar..." (el-Münafikun, 63/4) şekliyle temas edilmektedir. Her kuvvetli sesi kendi aleyhlerine sanmaları, onların korkaklığından kaynaklanmaktadır. Korku geldiği zaman insanlara yakın davranırlar, ancak ortalık sakinleşince yine insanlara hoş davranmazlar (İbn Kesir, 2017, 435). Bu şekilde gerçekleştirilen tutarsız davranışlar ancak zayıf kişilikli insanların gerçekleştireceği türden davranışlardır.

Kur'an'da sıklıkla dünya hayatının geçiciliğine, dünya nimetlerine aldanıp ahiret hayatını unutmamaya vurgu yapılmaktadır. Ancak gösterişçi insan, tüketimin yapay hazzına öylesine alışmıştır ki, o insanın kalbi hastalıklıdır, kulakları sağırdır, gözleri kördür (Süleyman, 2003, 33). Kur'an'da birçok yerde uyarılmıştır ancak bu uyarılar ona fayda hiçbir sağlamamaktadır. Sonunda pişman olan ve hezeyana uğrayan yine kendisi olur (İlgili ayetler için bk. el-İbrahim, 14/3; el-Kasas, 28/60). İslam dini sosyal bir din olmakla birlikte dinî pratikleri de olan bir dindir. Kur'an'da insana yapılan uyarıların amacı insanın dünya 
hayatı ve ahiret hayatı dengesinde kalmasını sağlamaktır. İnsanın, yaratıcısına ve inandığ1 kutsallara yabancılaşması engellenmeye çalışılarak, insanı dünyaya olan aşırı bağlılıktan kurtarmak amaçlanmaktadır (Altıntaş, 2005, 172-173).

\subsection{Amelî Açıdan Gösterişçi Dindarlık}

Tüketim kültürünün farklı bir boyut kazanmasıyla toplumda, yeni kimlik belirleyiciler ortaya çıkmaya başlamaktadır. Dinî pratiklere toplumsal görünürlük kazandırmak önemli kimlik belirleyicilerden olmaktadır (Özbolat, 2015, 155). Dinî pratiklere görünürlük kazandırmanın amaçlanmasıyla, ibadetlerdeki samimi duygular yerini gösteri duygularına bırakmaktadır. Dinin gerektirdiği pratikleri yapay duygularla gerçekleştiren gösterişçi dindar, çeşitli ibadetler ile kendini ön plana çıkarabilir. Bu tür kimselerin ibadetlerin manevi boyutuna inancı olmadığı gibi ibadetlerin kendisine faydası olacağına da inanmaz. Oysa insan, Allah'a kulluk için yaratılmıştır. Bu kulluğun gereği olan dinî pratikleri de şuurunu anlayarak ve içinden gelerek gerçekleştirmelidir (Namlı, 2018, 568). Gösterişçi dindar, ibadetleri insanlara rol yaparken kullandığ1 ve ibadetin ruhundan uzaklaştı̆̆ 1 için, faydasından öte zararı vardır.

Gösterişçi insanlar, ibadetleri insanlara duyurarak yaparlar; Nafile oruçlarını insanlara duyurarak tutarlar, hacca gittiklerinde ibadet boyutunu geri planda tutarlar. İbadetlerini Allah'ın rızasını kazanmak için yapmadıklarından, onlara oldukça zor gelmektedir. $\mathrm{Bu}$ davranış, kişilik açısından ikiyüzlülük olarak değerlendirilmektedir. Kur'an, davranışlarında samimi olmayan ve ikiyüzlü davranan insanı Allah'ın sevmeyeceğini belirtmektedir. (ilgili ayet için bk. en-Nisa, 4/36). Bu insanlar yalnızca kendilerini değerli görürler. Fakat Allah katında bir değeri olmayan, basit kimselerdir (İbn Kesir, 2015, 175). Samimi bir kalp ile yapılmayan ibadetler, şirk kapsamına da girmektedir. Çünkü Allah'ın emirleri kullanılarak, insanların övgüsü arzulandığı için Allah'tan başkası da amele ortak edilmiş olmaktadır. Bu durum, insanın kendine zulmetmesi olarak da değerlendirilmektedir. (Özdemir, 2015, 156). Gösteri amacıyla en sık kullanılan ibadetler namaz ve infak olmaktadir.

\subsubsection{Namaz}

Zamanla değişen tüketim kalıpları ile küreselleşen dünyada yaşayan insanlar, farklı nedenlerden dolayı (statü kaygısı, itibar kazanma vb.) gösteriş odaklı bir yaşam benimsemeye başlamaktadırlar. $\mathrm{Bu}$ insanların davranışları genellikle samimiyetten uzak duygularla gerçekleştirilmektedir. Bu tür samimi bir altyapısı bulunmayan davranışlar, insanların benliklerine, kişiliklerine ve inançlarına zarar vermektedir. İnsanlar tüketim kültürünü öylesine benimsemişlerdir ki kimi zaman çıkarları, inançlarının önüne geçmiştir. İslam dinine inanan insanlar için namaz önemli bir ibadet olmasına rağmen, sekülerleşen dünyada ibadetlerin insanlar üzerindeki manevi boyutları değer kaybetmektedir. Öyle ki

Journal of Analytic Divinity, https://dergipark.org.tr/tr/pub/jad Volume 5/1 
bireyler, ibadetleri menfaatleri uğruna birer araç edinmektedirler. Bu durum hem bireyin kişiliğine hem de ibadetlerin özüne oldukça zarar vermektedir. Dinî semboller, bu insanların çıkarları uğruna araç olarak kullanılmakta, özünden uzaklaşmaktadır.

Gösteriş̧̧i dindarlığın farklı boyutlarından birisi de gösterişle kılınan namazdır. $\mathrm{Bu}$ insanların asıl amacı namazı kılıyormuş gibi görünerek, toplum nezdinde itibar, saygı vb. gibi çıkarlar sağlamaktır. Öncesinde de belirtildiği üzere yapılan davranış, insanların dinî hassasiyetlerini istismar etmekten başka bir şey değildir. Gösteriş için namaz kılan insanlar, sürekli ibadet yaptıkları anlaşılsın diye dizleri eskimiş pantolonlar giyebilir. Yahut bu insanlar, namazlarını toplumun dikkatini çekecek şekilde kılarlar. Namazlarını genellikle camide ya da insanların göreceği toplu yerlerde kılmakla beraber, kendilerine kolay gelen vakitlerde (sabah namazına camiye gitmeyip, ikindi namazını camide kılmak gibi) kılarlar. Maun suresinde "Onlar namazlarından gaflettedirler, onlar sürekli gösteriş yaparlar." (el-Maun, 107/5-6) ayetleriyle münafıklardan bahsedilmekte ve riyanın benliklerine zarar verdiği vurgulanmaktadir.

Namazı yalnızca gösteriş için kıldıklarından dolayı çevrelerinde gösteriş yapabilecekleri insanlar olmadığında namaz kılmazlar. Münafıkların ibadetleri Kur'an'da (bk. el-Bakara, 2/264) kayanın üzerine gelip geçen yağmur damlalarına benzetilmektedir. Allah katında bir karşılığ da yoktur (Karaoğlan, 2019, 57-39). Kur'an'da, gösteriş ile namaz kılan ve bu namazda bir çıkar amacı güden kimselerin ibadetlerinin faydasız olacağı kesin bir şekilde söylenmektedir (bk. en-Nisa, 4/142-143).

\subsection{2. İnfak}

İslam dininde tekelleşmenin önüne geçebilmek adına zekât ve infak gibi mal ile gerçekleştirilen dinî görevler bulunmaktadır. Bu görevler bir malın tek elde toplanmasını engellemekle birlikte, ekonomik olarak düşük seviyedeki insanlara maddi fayda sağlamaktadır (Altıntaş, 2005, 62). Toplumsal bağlamda infak, insanlar arasında sosyal ilişkiler kurulmasını ve toplumda insanlar arasında ekonomik açıdan uçurum oluşmasını engellemektedir. İnfak ibadeti, inanan kimsenin samimi duygularla yapması geren bir görevdir. Ancak o şekilde geçerli sayılır ve manevi anlamda bir değeri olur. Samimi olarak infak yapmayan kimsenin niyetini Allah bilir. Bu kimsenin Allah'ın rızasını kazanma gibi bir niyeti de bulunmamaktadır. Bu kimseler, infak davranışında bulunurken, mallarını gereksiz harcadıklarını düşünürler. İstemeyerek verirler (Kasapoğlu, 2017, 32-33). Bu oldukça yanlış bir düşüncedir. Sosyal bir varlık olan insanın, dinî ibadetlerini gerçekleştirmesinin yanında; empati yapabilme ve cömert bir şekilde yardım yapabilme gibi insanî duygularının da gelişmesi oldukça önem taşımaktadır.

Gösterişçi dindarlarda dünya sevgisi, maddiyata bağlılık vardır. Sahiplenme 
duygusu onları hâkimiyet altına almıştır. Cimriler, mal biriktirir, zorunda kalmadıkça harcamazlar. Toplumla samimi ilişki kurmamakla birlikte, kurulan ilişkiler de çıara dayanır. Bu oldukça erdemsiz bir davranıştır. Münafık ölmeyecekmiş gibi mal biriktirir ama bu malın kendisine bir faydası olmayacağını düşünemez. Cimri insan, tükenir korkusuyla infakta bulunmaz. (Kasapoğlu, 2017, 294-298/ 278-280). Cimriliğin hoş bir davranış olmadığı Kur'an'da söylenmiştir ve yasaklanmıştır (İlgili ayetler için bk. elMuhammed, 47/38; el-Al-i İmran, 3/180). Maddi ibadetlerden biri olan infakın, toplumu birbirine yaklaştırma, insanları cimrilikten koruma, toplumdaki ekonomik eşitsizlikleri giderme gibi toplumsal yönleri de vardır. Kur'an her zaman dengeyi ve ölçüyü savunmaktadır. İnsanlar arasındaki birlik ve beraberliğin sağlanabilmesi için, ekonomik olarak dengeli bir toplum olması gerekir (Güngör, 2007, 184). İnfakta, veren, alan, kabul eden olmak üzere üç boyut vardır. Kabul eden Allah'tır. Samimi bir kalple yapılmadığı sürece hep bir boyutu eksik olur ve infak gerçekleşmiş sayılmaz (Kasapoğlu, 2017, 42). Yaptıkları hayırları gösteriş amacıyla ve insanları üzerek sevaplarını boşa çıkaranların durumu; çeşitli ağaçlarla ve meyvelerle dolu bir bahçeye vuran fırtınaya benzetilmiştir (bk. el-Bakara, 2/266) (Çakar, 2016, 298).

Gösteriş amacıyla yapılan infak Kur'an'da eleştirilmiştir (bk. el-Beled, 90/6). Allah katında bir değeri yoktur. İnfak yapılacağı zaman açıkça ve karşısındaki kişiyi incitecek şekilde yapmanın ahirette bir karşılığı olmadığı gibi, yardıma muhtaç kişiyi de üzer. Kur' an'da bu durumun tehlikeli ve faydasız olduğu "mallarını insanlara gösteriş olsun diye infak ederler." (en-Nisa, 4/38) belirtilmekte ve toplumsal beraberliği sağlayabilmek için insanların cömert olmaları, bencillikten sakınmaları gerektiği de vurgulanmaktadır.

Kur'an'da insanların samimi bir kalp ile ve birbirlerini incitmeden infak yapmalarının önemi açıklanmış ve ihlaslı davranmayan kimseler eleştirilmiştir (İlgili ayetler için bk. elBakara, 2/264; el-Müddessir, 74/6). Allah'ın ihlasla yapılan iyiliğin karşılığını fazlasıyla vereceği, ayrıca her yardım yapana değil ancak samimi bir kalp ile yapılan yardımın karşılığını verecektir (bk. el-Bakara, 2/261) (Nesefi, 2003, 2/147). İnsan, ihlaslı bir kalple sevdiği ve değer verdiği mallardan verdiğinde ibadeti kabul olmaktadır (Kasapoğlu, 2017, 196). Allah'ın rızasını kazanmak dışında başka bir niyetle Allah'a yaklaşmak, ihlasa manidir (Kuşeyri, 2009, 89). Zeyd b. Elsem, bir insana yardım yaptığında, selamının bile ona ağırlık vereceğini hissediyorsan, selam verme! buyurmuşlardır (İbn Acibe, 2011, 700).

Kur'an'da, (İlgili ayetler için bk. el-Leyl, 92/ 19-20; el-Bakara, 2/ 265; el-Bakara, 2/195; el-Bakara, 2/270-274; el-İnsan, 76/8; et-Teğabün, 64/17; et-Tevbe, 9/54) Allah yolunda infak etmeyi, infakta samimi olmayı, verilen malların aslında insanlara değil de Allah'a verildiğini ve karşılığını da Allah'tan alınacağından, münafıkların ise istemeyerek verdiklerinden bahsedilmektedir. Münafıklar, infaklarında samimi olmadıkları gibi, ihlasla ibadetlerini yapan Müminlerle de alay etmişlerdir. Durumu zayıf olup, Allah'ın rızasını kazanmak amacıyla ellerinden geldiğince yardım yapan Müslümanları akılsız olarak görmüşlerdir. Onları küçümsemişlerdir. İnfakta ki gaye, malın miktarı değildir. İnsanın

Journal of Analytic Divinity, https://dergipark.org.tr/tr/pub/jad Volume 5/1 
samimiyetidir (Kasapoğlu, 2007, 35).

\section{3. İtikadî Açıdan Gösterişçi Dindarlık}

İtikadî açıdan gösterişçi dindarlık münafıklıktır. Münafıklar, inanmadıkları hâlde inanmış gibi davranan insanlardır. Davranışları çıkarlarına göre şekillenir. İçinde bulundukları toplumun kalıplarına göre değişmektedir. Bu insanlar bencil davranışlarda bulunmaktadırlar. Kendileri başta olmak üzere, çevrelerindeki insanlara da saygıları yoktur. Yine bu insanların inandıkları kutsallar da bulunmamaktadır. Münafıklar, insani ilişkilerde de iki yüzlü davranırlar. Tüketim kültüründen etkilenen insanlar, toplumda kabul gören değerleri kullanarak onlardan bir çıkar elde etmeye çalışırlar ve daha fazla kazanma hırsı benliklerine öylesine işlemiştir ki kimi bireyler ekonomik açıdan fayda sağlayabilmek için dindarmış gibi davranmaktadırlar. Bu yapay dindarlık ise toplumun kutsallarını bir nevi hafife almak anlamına gelmektedir. Ticaretle uğraşan bir insanın, satışlarını artırmak ve dine bağlı kişileri de kazanmak amacıyla iş yerine dinî semboller koyması, gösteriş olarak algılanmaktadır. Bu duruma Kur'ân'da "Onlarnn ticaretleri kâr etmemiş, doğru yolu da bulamamışlardır." (el-Bakara, 2/16) ayetiyle temas edilmektedir.

Gösteriş̧̧i dindarlar, Müslümanların iyiliğini istiyor gibi görünüp, arkalarından iş çevirirler. Yahut Müslümanlara toplumun zor zamanlarında kendilerine zarar gelecek kaygısıyla destek olmazlar. Hendek savaşı esnasında da geri planda durmuşlardır. Savaş esnasında varlıklarını kaybetmekten çekinerek geride beklemişlerdir. Savaş sonrası ganimetler paylaşılmaya gelince büyük bir kıskançlığa ve hırsa kapılarak, Müslümanların yanındaymış gibi davranmışlardır (Kasapoğlu, 2017, 7/280-281). Müslümanların sahip olduğu maddi imkânlara ve siyasi itibara sahip olmayı istemektedirler (Okumuş, 2017, 279). "Rabbinden bir yardım gelecek olsa, o zaman da aslinda biz sizinle olduk derler ( el-Ankebut, 29/10). Kendi düşüncelerini kıyafetlerle, davranışlarla gizlediklerini sanarlar (bk. el-Hud, 11/5). İnsanların fikirlerini kıyafetlerle ve gösteri imgeleriyle sürekli olarak gizlemeleri mümkün değildir. Mutlaka bir şekilde açık vereceklerdir, elde ettikleri yapay itibar ve saygı bir gün yerle bir olacaktır.

Mü'minlerin meclislerine girer, sohbetlerini dinlerler. Bu meclislerden bir fayda sağlayamazlar, geldikleri gibi giderler. (İlgili ayetler için bk. el-Bakara, 2/8-14; en-Nisa 4/60,81; en-Nur, 24/47; el-Münafikun, 63/1,3; el-Maide, 5/61). Öyle ki münafıklar, Mü'minlerin arasına nifak sokmak, onlara zarar vermek amacıyla Dirar Mescidi'ni inşa etmişler. Mescidi, Müslümanların namazlarını kılmaları için yaptıklarını söylemişlerdir. Amaçları Müslümanlar arasında ayrılıklar çıkarmak ve Kuba mescidine zarar vermektir (İbn Kesir, 2015, 395). Peygamber'e, o mescitte namaz kıldırmaması gerektiği, mescidin kötülük amacıyla yapılan bir yer olduğu, Allah tarafından bildirilmiştir. Daha sonra ise

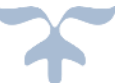


mescit Müslümanlar tarafından yakılmıştır, münafıklar amaçlarına ulaşamamışlardır (bk. et-Tevbe, 9/107-110).

Münafıklar, insanları aldatan, güvenilmez kimselerdir. Mü'minlerle karşılaştıkları zaman onlarla sözde samimi ilişkiler kurarlar, arkalarından da alay ederler ( İlgili ayetler için bk. el-Bakara, 2/9; en-Nisa, 4/142; 11/Hud,5). Allah, her şeyi bildiği hâlde onları imtihan etmektedir. Onlara yaptıklarının kötülüğünü fark edip, bu kötülüklerden dönme fırsatı vermektedir. Bunu anlamazlar, kötülüklerinden vazgeçmezler. Allah'ı ve Mü'minleri aldattıklarını düşünerek yalnızca kendilerine kötülük etmektedirler. Kendilerine yapılan uyarılara, imtihanlara rağmen doğruyu görmek istemezler, kendi tutarsızlıklarından vazgeçmezler (İlgili ayetler için bk. el-Bakara, 2/16; el-Muhammed, 47/16, 23-24).

\section{Sonuç}

Geçmişten bu yana var olan tüketim kavram1, küresel boyutta yeni anlamlar kazanmıştır. Dünya üzerinde ortak tüketim kodları oluşturulmuş, artan tüketim miktarının sonucunda, farklı ekonomik sistemler ortaya çıkmıştır. İnsanlar, çeşitli yöntemlerle tüketime teşvik edilmişlerdir. Değişen tüketim kalıplarıyla çevrilen dünyada, isteklerini ertelen insan değil de onları hemen satın alan insan tipolojileri oluşturulmaya çalışılmıştır. Tüketim çarkının bir an bile durmasına izin verilmemiştir. Reklam sektörü ve medya kuruluşları tüketimin gün geçtikçe daha da artmasına olanak sağlamıştır.

Modern insan, kendisini tükettikleriyle ifade eden insandır. Bu sağlıklı bir yöntem olmayıp, psikolojik ve sosyolojik açıdan bireyselleşme, yalan söyleme, kendine ve topluma karşı güvensizlik gibi birçok olumsuz sonuçlara neden olur. Ortaya çıkan olumsuz sonuçlardan bir diğeri ise gösteridir. Gösteri toplumlarında insanlar, tükettiği kadar var olduğu düşüncesiyle, sinırsız bir tüketim döngüsüne girer. Bireyler, zamanla kendilerini oluşturdukları ortak tüketim kodlarıyla, işaret değeri olan nesnelerle ifade etmeye başlarlar ve mutluluğu tüketerek elde etmeye çalışırlar. Artan tüketim bireylere hayal ettikleri mutluluğu getirmez, aksine kişiler hep daha fazlasını istedikleri için kendilerini yetersiz hissetmeye başlarlar. Bu durum, birçok psikolojik ve sosyolojik olumsuzluğa neden olmaktadır.

Tüketim kültürü insanların benliğine öylesine işlemiştir ki modern dünyada insanlar adeta her şeyi tüketmeye programlanmış robotlara dönüşmüştür. Tüketim kültürünün etkileri dinde bile hissedilir olmuştur. İnsan ile inandığı kutsal arasında olan bağ zayıflamıştır. İnsanlar dinî pratiklere de maddi anlamlar atfederek onlardan da kazanç sağlamayı amaçlayan bir varlıklara dönüşmektedirler. Bu durumda dini pratiklerin itibarını zayıflatmakla kalmayıp; kendilerine manevi açıdan fayda sağlayan din kurumunu da kaybetmektedirler.

Tüketim kültüründe insan, sahip olduklarını toplumda sergilediği ölçüde görünür olduğuna inanmaya başlamıştır. Toplum içinde dindar görünüp, yalnız kaldığında farklı 
davranan insan tipleri ortaya çıkmaya başlamaktadır. Bu şekilde gerçekleştirilen tutarsız davranışlar, insanların psikolojilerine de olumsuz yönde etki etmektedir. Bu insanlar, -mış gibi yaparak kişisel çıkarlarını önemserler. Bu çıkarlar, kişiden kişiye değişebilir. Gerçekleştirilen davranış, insanların dinî hassasiyetlerini kullanmaktan ve inanılan kutsallara saygısızlık yapmaktan başka bir şey değildir.

İslam'da, gösterişçilik hoş karşılanmamış ve Kur'an'da birçok yerde eleştirilmiştir. Gösterişçilik, pahalı kıyafetler, yapılan ibadetler ve insan ilişkileri gibi birçok durumda yapılmakta olup; yeri, zamanı ve şekli tamamen gösterişçi insanın en çok çıkar sağlayacağı zamanda ve şekildedir. İnsanların yüzüne gülüp, arkalarından alay etmek de alay eden kimselere bir şey kazandırmadığı gibi; diğer insanları küçük düşürmek ve değersiz hissettirmek, kişiyi yüceltmez. Bu davranışı gerçekleştiren kişinin, kişiliğindeki zayıflığın göstergesidir. Kur'an bağlamında da ahlak ve değerler bağlamında da etik bir davranış olmayıp, nahoş karşılanmıştır. Gösterişle yapılan ibadetlerin değeri ve karşılığı yoktur. Dinî değerleri hafife alma ve insanların gönlünü kırma gibi durumlar söz konusu olduğu için, gösteriş yapanlar cezalandırılacaklardır.

Sonuç olarak tüketim kültürünün etkileri sosyal, siyasal ve dinî alanlar başta olmak üzere birçok alanda hissedilmektedir. Sahip olduğu her şeyi tüketmeye, harcamaya ve ondan maddi veya manevi bir kazanç sağlamaya çalışan insan tipleri ortaya çıkmaya başlamaktadır. Kontrolsüzleşen tüketim alışkanları ve önüne geçilemeyen dünya sevgisi insanın benliğine ve inandığı değerlere zarar vermektedir. İnanılan kutsalların insanlar üzerindeki etkileri kaybolmaktadır, kutsallar araçsallaştırılmaktadır. Gösterişçi dindarlar, dinin meşrulaştırma gücünden faydalanmaktadırlar. Bunun sonuncunda ise her zaman daha fazlasını isteyen ve arzuları için tüm değerlerini ayaklar altına alan, yalnızca ve her koşulda kendi isteklerini önemseyen bencil insan tipleri yaygınlaşmaya başlamaktadır. Gösterişçilik, gerek toplumsal hayatta, gerek İslam dininde tasvip edilmeyen bir davranıştır. İnsanların olduğundan farklı davranması sosyal ilişkilerdeki güven duygusunu zedelemektedir ve toplumda insanlar arasında yapay ilişkilerin oluşması kaçınılmazdır.

\section{Kaynakça}

Açıkalın, Sezgin vd. "Veblen'ci Gösteriş Amaçlı Tüketim". Sosyal Ekonomik Araştırmalar Dergisi 4/7 (01 Haziran 2004), 1-18.

Adler-Nissen, Rebecca. "Stigma Management in International Relations: Transgressive Identities, Norms, and Order in International Society". International Organization 68/1 (Ocak 2014), 143-176. https://doi.org/10.1017/S0020818313000337

Allport, W. Gordon. Birey ve Dini. çev. Bilal Sambur. Ankara: Elis Yayınları, 2004. 
Altıntaş, Ramazan. Din ve Sekülerleşme. İstanbul: Pınar Yayınları, 2005.

Altuntaş, Halil vd. Diyanet İşleri Başkanlığı Kur'an’ı Kerim Meali. Ankara: Diyanet İşleri Başkanlığı Yayınları, 12. Basım, 2011.

Aydoğan, Filiz. “Tüketim Kültürünün Gölgesinde Kentler”. Marmara Üniversitesi İktisadi ve İdari Bilimler Dergisi 27 / 2 (11 Mart 2015), 203-215.

Bat1, Uğur. Tüketici Davranışlar Tüketim Kültürü, Psikolojisi ve Sosyolojisi Üzerine SSeytanın Notları. İstanbul: Alfa Basım Yayım Dağıtım, 2015.

Belhî, Ebü'l-Hasen Mukātil b. Süleymân b. Beşîr el-Ezdî. Tefsir-i Kebir. 3 Cilt. Beyrut: Darü'l-Kütübü'l-İlmiyye, 1. Basım, 2003.

Bocock, Robert. Tüketim. çev. İrem Kutluk. Ankara: Dost Kitabevi Yayınları, 3. Basim, 2009.

Çakar, Ferihan. "Amellerin Boşa Çıkması Bağlamında: Riya". Ekev Akademi Dergisi 66 (01 Ocak 2016), 289-289. https://doi.org/ 10.17753/Ekev602

Çiçek, Refikullah. İslam Ve Kapitalizm. Ankara: Kalkan Matbaacılık, 2012.

Çınar, Recai vd. "Tüketim Toplumunun Şekillenmesi ve Tüketici Davranışları Karş1laştırmalı Bir Uygulama-”. Atatürk Üniversitesi Sosyal Bilimler Enstitüsü Dergisi 13/1 (20 Nisan 2010), 277-300.

Dal, N.Esra. "Tüketim Toplumu ve Tüketim Toplumuna Yöneltilen Eleştiriler Üzerine Bir Arasstırma". Mehmet Akif Ersoy Üniversitesi Sosyal Bilimler Enstitüsü Dergisi 9/19 (30 Haziran 2017), 1-21. https://doi.org/10.20875/makusobed.311006

Demir, Recep. "Doyumsuz Tüketim Arzusu ve Çevre Sorununa Kuran Çerçevesinde Bakış / A View Within the Quran's Perspective to the Desire of Over- Consumption and Enviromental Issue". Journal of History Culture and Art Research 1/4 (25 Aralik 2012), 1-12. https://doi.org/10.7596/taksad.v1i4.105

Demirel, Songül vd. "Tüketim, Postmodernizm ve Kapitalizm Örgüsü". Ankara Üniversitesi Ilef Dergisi 2/1 (10 Haziran 2015), 115-138. https://doi.org/10.24955/ilef.305275

Demirezen, İsmail. Tüketim Toplumu Ve Din. İstanbul: Değerler Eğitimi Merkezi, 2015.

Duman, M.Zeki. Tüketimin Bireysel, Toplumsal ve Kültürel Etkileri. Ankara: Anı Yayınc1lik, 2018.

Eglitis, Daina. "Class, Culture, and Consumption:Representationsof Stratification in Post-communist Latvia". Cultural Sociology 5/3 (2010), 423-446.

İbn Acibe, Ebül-Abbâs Ahmed b. Muhammed b. Mehdî el-Hasenî eş-Şâzelî. Bahrü'l-Medid fi Tefsiri'l-Kur'ani'l-Mecid Kur'an'in Tefsiri ve Tasavvufi İşaretleri. İstanbul: Semerkand Yayınları, 2011.

Ertit, Volkan. Sekülerleşme. Ankara: Liberte Yayınları, 1. Basım, 2014.

Göle, Nilüfer. Seküler ve Dinsel Aşınan Sinırlar. İstanbul: Metis Yayınları, 2012.

Journal of Analytic Divinity, https://dergipark.org.tr/tr/pub/jad Volume 5/1 
Guevera, Ernesto Che. Gençlik Üzerine Yazılar. çev. Baran Aladanlı. İstanbul: Arya Yayınc1lik, 2016.

Güngör, Özcan. “Kur’an’da Sosyal Bütünlessme”. Diyanet İmi Dergi 43/2 (2007), 173-190.

Haşıloğlu, S.Burak vd. "Dindarlık Olgusunun Satın Alma Davranışı Faktörleri Üzerinde Etkisi". Tüketici ve Tüketim Araştırmaları Dergisi 4/1 (01 Ocak 2012), 1-18.

Hökelekli, Hayati. Din Psikolojisi. Ankara: Türkiye Diyanet Vakfı Yayınları, 4. Basim, 2001.

İbn Kesir, Ebu'1-Fida İsmail İmadu'd-Din ibn Ömer îbn Kesîr İbn Davud îbn Kesîr el-Dımaşkî el-Kureyşî. Muhtasar İbn-i Kesir Tefsiri. çev. Savaş Kocabaş. 10 Cilt, İstanbul: Karınca- Polen Yayınları, 2015.

İbn Kesir, Ebu'l-Fida İsmail İmadu'd-Din îbn Ömer îbn Kesîr İbn Davud îbn Kesîr el-Dımaşkî el-Kureyşî. Büyük Kur'an Tefsiri. çev. Abdulvehhab Öztürk. İstanbul: Kahraman Yayınları, 2017.

İlter, Esat. "Tüketim Kültürünün Tarihsel Gelişim Süreci ve Bireysel, Toplumsal ve Kültürel Etkilerinin İncelenmesi”. Erzincan Üniversitesi Sosyal Bilimler Enstitüsü Dergisi 12/2 (2009), 461-476.

İnce, Abdullah vd. "Tüketim Dinamikleri Ölçeği: Kurumsal Din Eğitimi Almış Bireylerde Tüketim Eğilimleri”. Cumhuriyet İlahiyat Dergisi 22/ 1 (15 Haziran 2018), 63-92. https://doi.org/10.18505/cuid.377688

İslamoğlu, A. Hamdi vd. Tüketici Davranışları. İstanbul: Beta Basım Yayım Dağıtım, 3. Basım, 2010.

Karaoğlan, Arslan. "Kur'an'da Anlatılan Münafik Tipolojilerinin En Belirgin Karakteristik Özellikleri -Nisâ 142-143. Ayetleri Örneği-". Eskiyeni 38 (20 Mart 2019), 45-76.

Kasapoğlu, Abdurrahman. Kur'an Psikoloji Atlast- Uygulamalı Psikolojik Tefsir. 8 Cilt, Ankara: Gece Kitaplığı Yayınları, 2017.

Koç, Mustafa. "Dindarlığın Oluşumuna Din Eğitiminin Psiko-Pedagojik Katkıları: 'Değer-Yoksun Dindarlık' Tipolojisi Bağlamında Teorik Bir Yaklaşım*” 15/ (2017), 87-138.

Köroğlu, C. Zehra. Tüketim Kültürü ve Din. Ankara: Gümüşhane Üniversitesi, 2012.

Kurt, Abdurrahman. "Dindarlığı Etkileyen Faktörler". Uludağ Üniversitesi İlahiyat Fakültesi Dergisi 18 / 2 (Haziran 2009), 1-26.

Kuşeyri, Abdulkerim. Tasavvuf İmine Dair Kuşeyri Risalesi. İstanbul: Dergah Yayınlar1, 2009.

Maslow, Abraham. İnsan Olmanin Psikolojisi. çev. Okhan Gündüz. İstanbul: Kuraldışı Yayıncılık, 2011. 
Miller, Vincent J. Consuming Religion: Christian Faith and Practice in a Consumer Culture. Newyork: Contiuum, 2003.

Namlı, Abdullah. "İbadetler ve Allah'ın Çeşitlendirilmiş Sevaplandırma Şekilleri”. Tasavvur / Tekirdağ İlahiyat Dergisi 4/2 (30 Aralık 2018), 564-598.

Nesefi, Ebü 1-Berekât Hâfızüddîn Abdullah b. Ahmed b. Mahmûd. Nesefi Tefsiri. 2 Cilt. İstanbul: Ravza Yayınları, 1. Basım, 2003.

Okumuş, Ejder. Gösterişçi Dindarlık. İstanbul: Özgü Yayıncılık, Lord Matbaası, 2. bask1, 2017.

Orçan, Mustafa. Osmanlı'dan Günümüze Modern Türk Tüketim Kültürü. Ankara: Harf Eğitim Yayıncılığı, 2008.

Özbolat, Abdullah. Kapitalizme Eklemlenme Dindar Orta Sinıfta Tüketim Kültürü. Adana: Karahan Kitabevi, 2015.

Özcan, Burcu. "Hedonizm ve Kimlik Temeline Dayalı Postmodern Tüketim Yaklaşımı". Istanbul Journal of Sociological Studies 0 / 35 (Eylül 2011), 119130.

Özdemir, Ahmet. "Kur'an'da İhlas”. Gaziosmanpaşa Üniversitesi İahiyat Fakültesi Dergisi 3/2 (01 Aralık 2015), 153-166.

Öztaş, Fatih vd. "Kimlik, Mekân, Kutsallık: Tüketim Mabetlerinde Kimlik Arayışı". Gümüşhane Üniversitesi İlahiyat Fakültesi Dergisi 9/ 17 (15 Ocak 2020), 111128.

Parılt1, Cemalettin. "Maslow'un İhtiyaçlar Hiyerarşisi Kuramında Kendini Gerçekleştirme”. Kamu-İş Dergisi 4 / 4 (1999), 267-277.

Pişkin, Mücahid. "Tüketim Toplumu'nda Din ve Dinî Değerler: Lüks Hac ve Umre Örnek Olay1". Insan ve Toplum, 6/2 (2016), 1-24.

Saad, Gad. The Evolutionary Bases Of Consumption. Mahwah: Lawrence Erlbaum Associates, 2007.

Solomon, Michael vd. Consumer Behaivour A European Perspective. New Jersey: Prentice Hall/Financial Times, 2010.

Subaş1, Necdet. Gündelik Hayat ve Dinsellik. İstanbul: İz Yayınc1lık, 2004.

Tan, Mehmet. "Tüketim Kültürü Bağlamında İstek ve İhtiyaçların Oluşumu: Kavramsal Bir Analiz". Firat Üniversitesi Uluslararası İktisadi ve İdari Bilimler Dergisi $3 / 2$ (31 Aralık 2019), 193-218.

Torlak, Ömer. Tüketim Bireysel Eylemin Toplumsal Dönüşümü. İstanbul: İnk1lâb Yayınlar1, 2016.

Ülken, Hilmi Ziya. Sosyoloji Sözlüğü. Ankara: Millî Eğitim Bakanlığı, 1969.

Veblen, Thorstein. Aylak Sinıfin Kuramı. çev. Cumhur Atay vd. İstanbul: Urzeni Yayınc1lik,2020

Weber, Max. Protestan Ahlakı ve Kapitalizmin Ruhu. çev. Zeynep Gürata. Ankara: Ayraç Yayınevi, 2008.

Yanıklar, Cengiz. Tüketimin Sosyolojisi. İstanbul: Birey Yayınc1lık, 2006.

Journal of Analytic Divinity, https://dergipark.org.tr/tr/pub/jad Volume 5/1 